\title{
Sonar: Empire, Media, and the Politics of Underwater Sound
}

\author{
John Shiga \\ Ryerson University
}

\begin{abstract}
This article traces the development of acoustic navigation media, or "sonar," in the first half of the twentieth century, focusing on the relationships forged between underwater sound, electric media, and new techniques of listening. The central argument is that sonar shaped, and was shaped by, the expansion of warfare and capital underwater, and that this expansion came to be conceptualized by nautical organizations as dependent upon the control of underwater sound. Through analysis of key episodes in the conquest of subsea space, the author explores scientific, military, and commercial efforts to sense underwater objects and demonstrates how these efforts helped reconceptualize oceanic water as a component of undersea acoustic media and led to the material reorganization of the ocean's acoustic field.
\end{abstract}

KEYWORDS Sonar; Military communication; Materiality; Subjectivity

RÉSUMÉ Cet article retrace le développement de médias acoustiques de navigation ou " sonars » dans la première moitié du vingtième siècle en mettant l'accent sur les rapports créés entre les sons sous-marins, les médias électriques et les nouvelles techniques d'écoute. L'argument central de l'article est qu'il y a eu une influence réciproque entre le sonar et l'expansion sous-marine de la guerre et du capital, et que les organisations nautiques ont commencé à concevoir cette expansion comme nécessitant le contrôle des sons sous-marins. Au moyen d'une analyse d'épisodes clés dans la conquête de l'espace sous-marin, l'auteur explore les efforts scientifiques, militaires et commerciaux pour repérer les objets sous l'eau et démontre comment ces efforts ont aidé à réaliser une nouvelle conception de l'eau océanique comme composante des médias acoustiques sous-marins, menant à une réorganisation matérielle du champ acoustique de l'océan.

MOTS CLÉS Sonar; Communication militaire; Matérialité; Subjectivité

\section{Down into sound}

"[T]here is more to modernity than meets the eye," writes Emily Thompson (2002, p. 19). No one perhaps knew this better than the operators of underwater listening systems, which were developed in the early twentieth century and which are today known as "sonar." In this article, I suggest that the development of underwater media for ocean navigation and surveillance was motivated and shaped by efforts to control movement across the ocean by military fleets and shipping cartels. These nautical organizations became interested and invested in the use of underwater sound to over-

John Shiga is Assistant Professor in the School of Professional Communication at Ryerson University, 350 Victoria Street, Toronto, ON M5B 2K3. Email: jshiga@ryerson.ca .

Canadian Journal of Communication Vol 38 (2013) 357-377

(C) 2013 Canadian Journal of Communication Corporation 
come a problem that had resulted from advances in ship design: as the size and speed of naval and commercial fleets increased during this period, ships became more vulnerable to an expanding array of underwater threats, from icebergs to submarines. Moreover, underwater hazards had become increasingly high-consequence risks for nautical organizations, since the destruction of massive, steel-clad ships like the RMS Titanic led to devastating losses of human life and property. The twentieth-century struggle to control horizontal movement across the ocean, whether in the imperial contest or commercial conquest, came to depend on the vertical extension of perception into subsea space. In the murky depths of the ocean, the ear became entrusted with the risky tasks of detecting, identifying, and locating otherwise imperceptible objects. The construction of a new technical-natural object- the underwater ear-exemplifies the new demands that were placed on hearing in the early twentieth century as the subsurface ocean became both an object and a channel of sensation, perception, and communication.

This article explores the development of underwater audio media in the first half of the twentieth century and suggests that these media crystallized dominant dispositions toward ocean sound and enabled profound changes in the material and symbolic construction of ocean space. I argue that the integration of underwater audio media into capitalist, military, and scientific activities propelled the transformation of the ocean from a flat surface for imperial and mercantile expansion-oceanic "transport surface," in Philip Steinberg's (2001) terms, or "ocean glacis," in Paul Virilio's (1986) - to a three-dimensional, subsurface "battlespace." This shift in understandings and modes of signifying ocean space had profound consequences for human uses of the ocean. My analysis highlights the ways in which underwater audio media reshaped the ocean's acoustic field for the enforcement of military and corporate monopolies of rapid and unimpeded transoceanic movement.

\section{Understanding underwater media}

Germany, France, England, and the United States were the principal investors in protosonar technologies, and the imperial ambitions of those nations played a significant role in the development of these underwater media. Scholars have long associated imperialism with certain modes of visual representation and practices of seeing; the sense of omniscience generated by realist representation, single-point perspective, and so forth provided an indispensable support for the imperial conquest of space (Harris, 2006; Harvey, 1989; Latour, 1990). These modes of representing and seeing the world enabled distant people and places to be classified and mapped in advance of invasion and occupation. Imperial visual culture also operated on the field of subjectivity, naturalizing identities and authorizing dispositions toward the world that facilitated imperial expansion (Hall, 1996; Said, 1979).

Drawing on critical work on forms of "aquatic media" through which the ocean has been mapped, sampled, measured, imaged, sounded, and apprehended as an object of knowledge and control, this article explores the sonic dimensions of the twentieth-century imperial expansion into the subsurface ocean (Burnett, 2009, 2012; Christie, 2012; Frost, 2001; Goodwin, 1995; Helmreich, 2009; Hohler, 2002; Roof, 2004; Steinberg, 2001; Weir, 2001, 2006). The development of underwater communication 
media in the early twentieth century, and the subsequent competition between different underwater media systems, is an important and, I believe, overlooked media transition that affected both imperial and capitalist expansion. In conceptualizing sonar as an medium of communication, I am drawing from Harold Innis' (1951) medium theory, which provides a materialist approach to media as bodily extensions and expressive forms that constitute an important part of the material conditions that give shape to perception, thinking, and organization (Angus, 1998).

The concept of bias, which denotes the medium's emphasis on space or time relative to other media, is helpful for tracing the way early underwater media articulated and reinforced their users' preoccupations with space or time, transmission or recording, sending or storing, circulation or accumulation. While the notion of bias is commonly used to refer to the physical characteristics of media (e.g., durability and portability), a closer reading of Innis' (1951) work suggests that space and time bias cannot be reduced to the medium's "technical specifications," because bias is conferred by the medium's interaction with its social and natural environments. ${ }^{1}$ Moreover, space and time, or transmitting and recording, are not polar opposites or mutually exclusive categories. As John Durham Peters (2003) argues, "To send a message (transmission), it must be preserved from death or corruption in transit (recording) ... to record, one must alienate the original by sending its data somewhere else ... sending and saving are twin faces of the same communication circuit" (p. 404). Bias is a matter of emphasis, and it arises from the whole set of social practices of accumulation and circulation that occur across the medium's extended infrastructure. As Ian Angus (1998) explains:

We should notice that in Innis' historical discussions the social influence of a medium of communication is always analyzed in relation to the whole environment in which it operates. It is not an isolated thing but the central factor within a complex environment made up of many media of communication and the objects they carry or reckon with as contents. Its bias has to do with its influence on the whole of this environment. Thus, the intrinsic characteristics of the medium, which is a certain organization of perception, institutions, and thought, lead in a given environment to effects of re-organization of that environment. (para. 19, emphasis original)

In the case of underwater media, the "whole environment" includes other print and electronic media, systems for training and attuning the senses to minute differences in ocean sound, the division of perceptual labour in processes of navigation and targeting, and modes of procuring "raw materials" required for the production and operation of devices.

Innis' (1951) case studies of communication and empire emphasize the importance of controlling the supply of material substrates for signification in order to build and maintain a monopoly of knowledge. Indeed, much of the early discourse around sonar concerns the difficulty of using electronic devices to transform ocean sound into a reliable substrate for the signification of underwater threats. The transition between different types of sonar is bound up with changes in what Lisa Gitelman (2004) calls the "material meanings" of media, that is, the "nexus of cultural practices, economic structures, and perceptual and semiotic habits that make tangible things meaningful" (p. 203). When 
new alignments of these cultural, economic, and perceptual-signifying elements gain traction in particular institutions or in the broader culture, the material meanings of media and of their material substrates (e.g., stone, paper, sound, light) become unstable and are open to redefinition.

In the context of underwater media, this struggle for control of the supply of material substrates or "raw materials" played itself out in what Steve Goodman (2010) calls the "politics of frequency," where different "vibratory forces" or frequencies are "captured, monopolized and redeployed" (p. 11). Competing underwater audio media were premised on different ways of monopolizing "vibratory force." The first systems developed for underwater acoustic detection were "passive" detection systems, so named because they were listen-only systems wherein a hydrophone (underwater microphone) picked up sound waves in the water and converted them into airborne sound audible to the operator. The devices, practices, and organizations of hydrophonic listening articulated a concern with the problem of controlling ocean space, specifically, the flat surface or glacis of imperial expansion. Hydrophonic listening facilitated centrifugal movement toward the boundaries of empire while underwater warning bells dotted along the shores acted as acoustic outposts, which maintained centralized control over the audible border between the inside and outside of empire.

As demonstrated by the German U-boat campaign during the First World War, hydrophonic listening could be used to navigate submarines toward their targets, enabling the German navy to disrupt the glacis model of the ocean. Demand for an alternative to hydrophonic listening emerged in the U.S., Britain, and Canada, seeking more accurate means of detecting and tracking German U-boats in the Second World War. Competition to the hydrophonic system emerged in the form of "active" detection technology, which transmits an acoustic pulse (or "ping") into the water and detects echoes caused by the pulse's reflection off of objects. The shift toward active detection helped constitute the subsurface ocean as a battlespace for submarine warfare and led to the construction of new infrastructures of sonar production, new formations of listening subjectivity, and new imbrications of technical, economic, and natural worlds, particularly in the procurement of clear frequencies and raw materials such as huge quantities of piezoelectric quartz from far-flung territories for use in the sonar transducers (Thompson, 2007). The massive scale of active detection infrastructure, training, and operations during the Second World War induced a shift in perceptions of the ocean. As nautical organizations attempted to dominate the deep sea by means of weaponized sound, attention shifted from the problem of space to the problem of time. A new hermeneutics of undersea echoes began to take shape around the interpretation of "pings" as recordings of an environment etched in a sound wave and the discernment of time delays between pulse and echo as signs of a distant presence.

\section{The aural border of the ocean glacis}

Early in the morning on April 15, 1912, RMS Titanic, the largest passenger ship that had ever been built, struck an iceberg. Within two hours, the ship sank to the bottom of the North Atlantic, killing 1,49o people. It was, and still is, the deadliest peacetime disaster in British history (McLean \& Johnes, 2000). The report commissioned by the British government, known as the Mersey report, found that the ship had sunk "due 
to collision with an iceberg, brought about by the excessive speed at which the ship was being navigated" (McLean \& Johnes, 2000, p. 731). It was standard practice in the shipping industry to continue on course and maintain speed in icefields. Despite mounting criticism of the governmental regulators and shipping and communications firms involved in the disaster, the "shipping industry blocked any serious discussion of the disaster in Parliament" (p. 729).

While popular accounts of the Titanic disaster tend to focus on the unexpected fragility of the ship, public debates and government inquiries surrounding the disaster demonstrated the extent to which the sinking of the Titanic called into question what John Law (1986) calls the "protective envelope," that is, the set of knowledges embodied by mariners, media, and ships to ensure the durability of ships and the dominance of the sea. As Law writes, "[T]he right documents, the right devices, the right people properly drilled - put together they would create a structured envelope for one another that ensured their durability and fidelity" (p.154). Only in conjunction with mariners drilled in astronomy and with new maps and other printed documents did the modifications in ship design acquire such importance in the way the Portuguese empire dominated far-flung territories beginning in the early fifteenth century. Military and commercial control of the ocean had, by this time, been based on a model of the ocean as a nautical glacis or "transport surface," which cannot be claimed as territory and which therefore facilitates unrestrained outward movement.

The protective envelope describes the technical and social means by which the ship senses and controls its relation with its environment. By the turn of the twentieth century, the increase in the scale and speed of ocean traffic had reached a critical threshold: speed exceeded the capacity of crews to sense and avoid hazards as well as the capacity (and willingness) of states to effectively regulate the design and use of the new steel-clad, coal-powered behemoths. ${ }^{2}$ Visual means of detecting hazardsmaintaining lookout points; keeping watch; reporting and communicating sightings; using maps, binoculars, and light stations and other reference points-were quite effective for avoiding hazards prior to the introduction of motor power. By the turn of the twentieth century, visual monitoring of the ocean was not particularly reliable, especially for mobile threats such as icebergs and submarines. Moreover, the visual means of detection did not offset increased risk of collision stemming from the acceleration of ships and the resulting decrease in warning time. Mobile hazards increasingly came to matter in transoceanic transportation, but they could not be reliably mapped or sighted in advance.

In the immediate aftermath of the Titanic disaster, efforts to develop a solution focused on technological fixes rather than institutional reforms to prevent such disasters in the future. Among the scientists inspired by the Titanic disaster were Reginald Fessenden, a Canadian scientist who developed the first sonic technique for underwater detection, and Constantin Chilowsky, a Russian émigré who, in collaboration with French physicist Paul Langevin, developed the first ultrasonic detection technique (Hackmann, 1984; Weir, 2001). Navigation companies and governments commissioned these entrepreneurial scientists to develop devices that would allow ships to detect approaching objects by means of underwater sound. Rather than conceptualizing the 
protective envelope in terms of the institutions that might regulate imperial and corporate movements across the glacis, navigation firms raced to exploit the speed of underwater sound to develop more efficient means of signalling and detecting hazards. In this way, the growing preoccupation with accelerating the transmission of navigational information buttressed the glacis model of the ocean and, in the long run, extended the conquest of space below the surface. ${ }^{3}$

The first commercial system for warning ships of underwater hazards was developed by Elisha Gray, who had also invented the telephone (independently of Bell), and A.J. Mundy. Underwater bells were placed near rocks, wrecks, and other hazards and were rung electrically, pneumatically, or by means of wave power. Ships could hear the warning bells through an underwater microphone, which Gray called a "hydrophone." Like all sound reproduction technologies, the hydrophone reproduced sound through transduction, that is, the conversion of "sound into something else and that something else back into sound" (Sterne, 2003, p. 22). As Jonathan Sterne and Mitchell Akiyama (2011) argue, the human ear is a transducer in the sense that it converts sound into electrical signals that the brain can understand. However, having evolved to sense sound in air, humans' built-in transducers do not perform well underwater. Waterborne sound needs to be converted into airborne sound to be heard clearly by human ears. Gray's hydrophone did this with a metal diaphragm, which was fitted to a carbon button microphone. The hydrophone received sound in water, transformed it into electrical signal, which could then be transformed again into sound in air. In 1899, Gray and Mundy received a patent for the automatic warning bell (Hersey, 1977). Mundy, Joshua B. Millet, and Edward C. Wood purchased the patent to the hydrophone from Gray in 1901 and founded the Submarine Signal Company (SSC) to further develop and market the warning bell system (Hackmann, 1984). By 1912, the SSC had established over 100 shore stations to operate warning bells marking underwater hazards in Europe, Asia, and North America (Frost, 2001).

The warning bell system was a response to the destabilization of the material meanings of optical detection media and of light more generally in the context of accelerated transoceanic movement. Since light does not penetrate very far below the surface, efforts to control undersea space tended to focus on sound. The warning bell system also altered the material meanings of underwater sound: the hydrophone operated as an interface between the previously separate worlds of airborne and waterborne sound, and the bells altered what one could expect to hear underwater. Moreover, underwater sound was organized to signify symbolically through the association of hazards with the bell sound in nautical culture. Finally, the acoustic field of the ocean was divided into signal (bell ringing) and noise (everything else), and the signals were spatially organized to form aural borders around the edges of hazards so as to repel ships.

At first, the system seemed to work quite well. Under ideal circumstances, the sound of the bell could be heard by a ship up to 15 kilometres away (Hackmann, 1984). In ordinary usage, however, listeners were unable to hear the sound of the bell against the various noises emanating from their own ships and from the sea. In 1912, the SSC approached the Canadian inventor Reginald Fessenden to develop a method for re- 
ducing noise in the system. The SSC believed the best solution was a more selective hydrophone to filter out all sound except those emanating from the bells, and it contracted Fessenden to design the improved listening device.

In January 1913, Fessenden delivered to the SSC a prototype of the new listening device, which he called the "vibrator" but was later dubbed the "Fessenden oscillator." It was the first magnetostrictive transducer that could convert sound into electrical signal and vice versa and could thus be used "actively" to transmit sound into the water and "passively" to receive underwater vibrations and convert them into sound for the listener (Frost, 2001, p. 469). Moreover, as the name "oscillator" suggests, the device could switch rapidly between these two modes; as soon as it transmitted sound into the water, the device would become a receiver, allowing the listener to hear the echoes of the transmission that had occurred fractions of a second earlier.

From the SSC's perspective, the oscillator would act as a selective or filtering hydrophone for picking up the sound of auditory beacons. The moving coil of the oscillator could be tuned to resonate in response to the frequencies in a particular range. If tuned to the frequency of the underwater bells, the oscillator would transmit the bell's sound to the operator while suppressing most other sounds. The oscillator's active mode, on the other hand, was a deviation from the existing system and arguably violated the terms of Fessenden's contract; by switching to active mode, the oscillator could generate continuous sound waves underwater, a use which the SSC had earlier rejected. The SSC expected a new type of underwater microphone; Fessenden produced instead a rather strange device that acted as both a receiver and a transmitter.

Fessenden himself envisioned the device as an echo-ranger, that is, as a device that generates a pulse which travels through the water and, somewhat like a probe, returns to the ship if it encounters an object. The operator would then calculate the threat's distance from the ship using the delay between transmission and echo. In this way, the oscillator was designed to operate as a self-contained system which, by radiating sound and then picking up echoes reflecting off of underwater objects, enabled realtime sensing of the environment. It was, in Fessenden's view, a far superior system than underwater sound beacons. However, despite successful tests of the oscillator in its active, sound-generating mode, the SSC decided to market the oscillator as a passive (listen-only) device (Frost, 2001). While the SSC eventually marketed the device in its active mode, this use was constrained to underwater Morse code transmission. The company refused to promote the oscillator as an echo-ranging device, or, to use Fessenden's Titanic-inspired term, as an "iceberg detector," until the end of the First World War.

Early in the development of proto-sonar technologies, there was considerable disagreement about the material meanings of the emerging medium. Should the focus be on high speed and direct transmission of predetermined information from beacon to ship, or on the continuous probing and decipherment of the environment by means of indirect sound? The dispute between the SSC and Fessenden about what sort of medium the oscillator would be was shaped by competing views about the appropriate model of signification for underwater sound technologies. The SSC's insistence that Fessenden build a more selective hydrophone attended to the question of fidelity in 
sound transmission, which in this case turned on the capacity of the hydrophone to reproduce the sound of the bell at a distance. The hydrophonic bell system was oriented toward communicating "danger" in bell ringing throughout the world's oceans. Warnings were thus encoded in a form that would be rapidly and reliably transmitted from hazard to ship by means of bells or between ships via Morse code. Fessenden's oscillator, in contrast, bounced sound off of objects and thus turned the issue from the problem of faithful transmission to the problem of how to interpret echoes as recordings of a prior presence. The SSC's acoustic outposts encouraged the outward movement of capital to non-capitalist regions; Fessenden's oscillator embodied a concern with the extension of the British empire in time through the increased durability of its ships. ${ }^{4}$

Whereas the SSC's system was based on symbolic signification, the oscillator crystallized the acoustic principle that disturbances in a sound wave are indices of the objects and events that caused them. Fessenden sought to exploit the particularities of transmission, such as changes in direction, velocity, and loudness, which act as recordings produced by the wave's transit through the water and its contact with particular objects. If fidelity is the goal, as it was in the hydrophonic bell system, then echoes are at best glitches or artifacts, an excess of signal that distracts the listener from the intended message. As an echo-ranger, the oscillator instead exploits the bounciness of sound, using indirect or reflected sound as an index of presence and the delay between transmission and reception as a mark of distance. The SSC wanted to offer mariners a sonic analogue and supplement to the long-established lighthouse system with only one sign to listen for: the ringing bell. Fessenden's echo-ranging system required the SSC and its clients to accept the then-new idea that sound is a compression wave that propagates, bounces, frays, and decays in complex but nonetheless predictable ways in water. As an echo-ranger or "iceberg detector," the oscillator required the SSC and the shipping industry to believe that echoes can act as reliable signs of presence, and it also implied the need for a new taxonomy of echoes for sensing, and making sense of, indirect sound returning to the ship. The SSC wanted a device to exploit the ocean as a passive conduit for transmission. Fessenden offered instead a device that would enable the ocean to record itself in sound waves.

The two interpretations of the oscillator-as-medium were also based on conflicting models of the distribution of agency in underwater communication. Whereas the SSC's warning bell assumed that humans need to speak for underwater objects since those objects do not transmit sound that is meaningful to humans, the oscillator assumed that objects communicate their presence by bending, splitting, absorbing, and reflecting the sound waves around them. In speaking for submerged objects, the bell system treated sound as an extension of a central authority that would determine the objects to be designated as hazards and would transmit signs associated with hazards to mariners in order to guide their actions. The oscillator activated sound as an extension of what Angus (1998) calls "bodily kinesthesis," through which the mariner traces the contours of the subsurface world as the ship moves. Two starkly different models of communication and knowledge distribution thus emerge at the juncture of hydrophonic listening and echo-ranging. For the SSC, the task of underwater com- 
munication was to convey pre-existing knowledge between two points in space as quickly as possible. The oscillator demanded that mariners internalize acoustic principles in order to produce knowledge from the oscillator's sonic communication with the local environment.

Finally, the two visions of the oscillator-as a real-time sensor and as a receiver for beacons - crystallized conflicting constructions of the space of commercial seafaring. The hydrophonic beacon system constructs that space as bounded; such a system perhaps more directly appeals to striated global space, parcelled out as centres and margins within the competing powers of industrial capitalism. The acoustic infrastructure maps onto and encloses the space of capitalism. Warning bells not only signify hazards but also the prior presence of imperial and corporate power, which marks and manages nautical space with light stations, buoys, and, now, warning bells. Fessenden's techniques, on the other hand, proposed that each ship could potentially sail beyond the boundary of the empire and remain cognizant of its invisible subsea surroundings. Moreover, each ship would become a part of a widely distributed system for the production of knowledge about uncharted and unmarked territories, mapping hazards that might otherwise obstruct the smooth surface of imperial expansion.

While the hydrophone and oscillator had not yet been deployed in a system resembling today's sonar technologies, they embodied the imperial conceptualization of the ocean as a smooth surface for rapid transport. One question that arises at this stage is why the SSC and its clients did not attempt to use the technologies at their disposal for sensing the environment (rather than signalling it). Publicly, the SSC ensured that Fessenden's echo-ranging proposal did not compete with the SSC's very successful warning bell system. As Gary Frost (2001) notes, however, the SSC sent a board member to market the technology to the German navy (and chose not to tell Fessenden), while Fessenden also proposed the oscillator's use as an echo-ranger to the British Admiralty (and chose not to tell the SSC). While it may be true that Fessenden did not make much of an impression on the British Admiralty, the latter took a keen interest in the oscillator, which had ramifications for the development of undersea warfare in the coming years.

Early in the First World War, British military laboratories attempted to adapt Fessenden's oscillator to the needs of anti-submarine warfare. The challenge encountered in this work stemmed from the slippery material meanings of echoes; listeners had difficulty distinguishing between echoes (signal) and reverberations (noise) using the valve amplifier technology of the time (Hackmann, 1984). In the absence of perceptible differences between underwater sounds, the meaningfulness of echoes as indices of presence and their strategic value in destroying submarines could not be stabilized. Subsequent phases of underwater acoustic research thus hinged on the capacity of researchers to divide the broad field of underwater sound into useful categories and to train listening subjects to perceive the ocean through that system of sonic division.

\section{The weaponization of underwater sound}

With the onset of the First World War, which Martin van Creveld (1985) describes as "the first war to be waged mainly by machines rather than by men" (p. 184), the German submarine or U-boat had displaced icebergs as the primary threat to transat- 
lantic shipping. U-boats were fully submersible warships that could hide below the surface, emerge quickly to fire torpedoes, and submerge again to escape retaliation. Early in the war, the German military realized that the U-boat would be most effectively deployed against merchant ships, since this would choke off supply lines that were required for machine warfare (van Creveld, 1989). With the German High Command's declaration of unrestricted submarine warfare, the threat to Allied shipping became clear. ${ }^{5}$ The U-boat prompted a shift in British and American thinking about the ocean. "As in virtually every other aspect of naval warfare," Gary Weir (2001) writes, "the submarine forced the navy to think and explore in three dimensions" (p. 153). In this section, I describe the manner in which sonar research during and between the First and Second World Wars enacted a notion of sound-as-weapon, which in turn contributed to the construction of the ocean-as-battlespace or a "force field" for the projection of power (Steinberg, 2001).

While advances had been made in hydrophones (especially their amplification), and newly formed research and development groups in the U.S. and Britain were beginning to experiment with active detection, the U-boat threat had the effect of rushing older equipment into service during the First World War. The purpose of this gear was to allow naval escorts protecting transatlantic convoys to listen for what was called the "hydrophone effect" or the various sounds emitted by U-boats, such as the collapse of cavitation bubbles around the propellers and the flow of water around the hull. Under ideal circumstances, these hydrophones were also sufficiently sensitive to pick up the sounds of machinery inside the U-boat (Llewellyn-Jones, 2006). In the U.S., thousands of T-shaped hydrophones were manufactured and fitted on the bottom of warships (Weir, 2001). The receivers on each side of the " $\mathrm{T}$ " were wired to a stethoscope through which the operator monitored subsea sound around the ship. By turning a metal handle, the operator could rotate the hydrophone and "scan" 360 degrees around the ship. The approximate bearing or direction of the sound's source could be determined by rotating the hydrophone until the sound was at its maximum intensity. For its part, the British government issued "drifter set" hydrophones (based on Elisha Gray's device) to fishing trawlers, where the usual drifter nets were replaced by drifter hydrophones (Lasky, 1977). These trawlers and their crews were enlisted into hydrophone flotillas, which consisted of three merchant search vessels and a naval support ship, to search 30-mile squares of the ocean (Hackmann, 1984). As with Gray's hydrophonebell system, the noise of the search vessels (propellers, engines, sloshing water, etc.) overwhelmed the sounds of distant targets, so the ships cut their engines three times per hour in order to hear the ocean more clearly. The SSC took a different approach to the problem of noise with its "Dinosaur" device, which was a passive hydrophone designed to be towed behind the ship and away from the engine. While these systems proved useful for detecting submarines, the difficulty of determining the target's location (especially its range) with listen-only equipment remained a problem though the end of war (Llewellyn-Jones, 2006).

While Hackmann (1984) points out that "in terms of kills, the hydrophone flotillas were a disappointment" (p. 69), this assessment misses what is perhaps the most significant and enduring result of this intensive and widespread process of sonic 
weaponization: the enactment of a new model of subsurface space as a combat environment by newly formed anti-submarine research organizations, such as the British government's Board of Invention and Research; by citizens, who submitted thousands of novel anti-submarine techniques to the British government; and by listeners on naval and merchant vessels who probed large swaths of the Atlantic Ocean with electric ears. One of the most important effects of this mobilization of hydrophone-based listening systems stemmed from the presence of listening devices rather than from their actual use in tracking submarines; the mere possibility that ships might be able to hear submarines approaching forced the latter to adjust their tactics. The redefinition of the ocean as a key battlespace in the "machine war" of 1914 to 1918 also led to the use of sound to bring targets closer in order to attack them. The subsea battlespace model emphasized the importance of "making contact" in the acoustic field as a part of the deployment of destructive force. Whether by torpedo, gunfire, depth charges, or nuclear weapons, destroying submarines came to be seen as dependent on the coordination of human and machinic senses to "solve" or "fix" the target. Isolating a target in the acoustic field and separating it from ocean noise became the necessary first step toward destroying it. By the end of the First World War, the weaponization of underwater sound involved not just the extension of the ears underwater, but also their selective numbing to sounds classified as noise. The effort to separate signal and noise was articulated in new scientific problematizations, new media infrastructures, and, as I discuss in the next section, new forms of listening subjectivity.

The transformation of underwater sound into a weapon depended on the redefinition of the problem of submarine detection. Until the interwar period, research in both active and passive detection tended to focus on the problem of how to amplify the signal so as to cut through the myriad noises in the water. This was particularly clear in the active detection work of French physicist Paul Langevin, whose ultrasonic quartz transmitter, according to his own report, was so powerful that it could send clear signals through eight kilometres of ocean water and kill fish swimming through the acoustic "beam." ${ }^{\circ}$ During the interwar period and continuing through the Second World War, research moved beyond the question of transmission (how to amplify distant signals) to broader questions about the ocean's mediation of sound. Although gradual, this redefinition of the problem of anti-submarine warfare shifted attention from upgraded devices to better understandings of the physical and biological processes that shape vibratory force underwater. The problem was not so much how to make sound pierce the water but rather how to incorporate the lattice of sound channels and barriers in ocean water as a component of the communication medium.

Weaponization also required the creation of institutions to develop and coordinate large-scale acoustic research programs. Government agencies in the U.K. and U.S. established new research facilities and organizations aimed at generating "productive dialogue between naval culture and the scientific community" (Weir, 2001, p. 105). With the onset of the First World War, the "haphazard" development of sonar by various entrepreneurs and firms came to an end and governments on both sides of the Atlantic began financing acoustic research and steering it toward anti-submarine warfare. ${ }^{7}$ The effort to harness underwater sound to counter the U-boat threat during the 
First World War also spurred the formation of new alliances between ocean science and the Navy as well as the development of international networks for the communication of research findings and technological innovations between Allied countries (Weir, 2001). ${ }^{8}$ While funds dried up in the 1930s, Vannevar Bush and other prominent American scientists successfully lobbied President Roosevelt and Congress at the outset of the Second World War to increase funding for military research, including sonar research in the Undersea Warfare division of the newly established Office of Scientific Research and Development (Lasky, 1977).

In order to render weaponized sound effective underwater, the Allied navies had to mobilize the concept of underwater sound as weapon from the laboratory to a geographically dispersed infrastructure (research and development, raw material supply, manufacturing, etc.) — the "long tail" of sonar as a medium of communication-and at the same time monopolize these vast infrastructures. The tension between mobilization and monopolization became evident in the attempt to secure supplies of piezoelectric quartz, which French, British, and Canadian sonar manufacturers used as the raw material for transducers in their active detection systems from the First World War through the Second World War (Hackmann, 1984). During the Second World War, raw quartz was mined in Brazil and shipped to the United States (for use in radios) and to Canada, where it was cut and polished by workers at the Department of Mines and Resources plant in Renfrew, Ontario (Pritchard, 2011). Workers managed to produce thousands of these active detection sets during the war, but the raw quartz supply was unstable due to the time required to ship huge volumes of quartz from Rio to Renfrew. Compounding this problem was the presence of marauding U-boats along the coasts of North, Central, and South America, which led to the decision to reduce the volume transported on each ship (Thompson, 2007). Due to these persistent pressures on the supply chain, authorities in Canada and the U.S. shifted their attention to strategies of accumulation through, for example, import controls, "critical mineral" laws, and government-controlled stockpiles (Thompson, 2007). Whereas passive detection systems could be produced from relatively common materials used in electronics manufacturing, the shift to active detection led to a new emphasis on problems of time: stabilizing the raw quartz market, preserving fragile quartz plates, maintaining stockpiles, and, perhaps most importantly, ensuring the enemy remained cut off from materials vital to underwater perception.

The mechanical hydrophone systems deployed in the First World War anti-submarine campaign, particularly those with multiple hydrophones developed in the U.S., enabled operators to "focus" their listening to a narrow portion of the acoustic field in order to detect submarine sounds and to extract from those sounds locative information. Even if these World War I era hydrophone listening systems fell short of the expectations of scientists and naval officers, such systems effectively crystallized the militarized conceptualization of underwater sound as acoustic force. This weaponized conceptualization of underwater sound displaced the older sense of underwater sound as vibratory radiation, as embodied by the underwater warning bell system. In order to activate weaponized sound, however, empire required a new type of listener. 


\section{Sonar's subjects}

During the First World War, the submarine problem was understood primarily as a technical matter of amplifying the message by adjusting the signal-to-noise ratio of listening gear. The submarine threat was redefined during the interwar period as a problem of producing knowledge about the medium of water. As this knowledge about the sound-conducting properties of water was incorporated into machines and bodies, a new form of tactile navigation emerged based on techniques of establishing and maintaining acoustic contact with objects in the water. This form of navigation emerged in the context of ultrasonic echo-ranging systems, which, by the Second World War, had displaced sonic echo-ranging devices based on Fessenden's design. ${ }^{9}$ The British and American navies were attracted to ultrasonics because their higher-frequency transmissions were less susceptible to disturbance by water variations than mid-frequencies and could thus travel farther and be aimed more precisely. This shift in technologies altered the experience of oceanic sound; sonar operators were trained to exploit "good" water conditions where sound seemed to "project" outwards to the target with little resistance from the water or from organisms suspended therein. The weaponization of ultrasound also altered modes of signification and perception of the subsurface ocean. Sonar operators were compelled to internalize the new indexical language of underwater media (the capacity of ocean sound to act as material traces of the "contact of interest") so that navies could exploit sound as vibratory force in the subsurface battlespace. Consequently, the older disposition toward ocean sound as a medium for the transmission of symbols with predetermined meanings gradually faded during the anti-submarine-warfare preparations of the interwar period.

As discussed in the previous section, a key component of active sonar is the transducer, usually made of a piezoelectric quartz or Rochelle salt, which converts the mechanical energy of underwater sound into electrical charges and vice versa. The transducer enabled active sonar to suppress noise by switching rapidly between transmitting and listening modes, allowing the operator to hear the echoes but not the original pulses. The operator calculated range (or distance) to the target by measuring the time delay between the device's transmission and the echo using a stopwatch, the visual displays of automatic rangefinders, or electrochemical recorders that plotted the target's movement on paper. Sonar operators engaged in monitory listening by "sweeping" or rotating the acoustic beam under the ship, a few degrees at a time. Upon hearing an echo, the operator would sweep back and forth to find the edges of the "contact of interest" and report the range and bearing so that depth charges could be targeted and launched. By the end of the First World War, seven Royal Navy ships were fitted with active detection gear. Active detection became the focus of anti-submarine research during the interwar years in the U.S. and in many European countries, with the exception of Germany, which was restricted from developing or using active sonar by the Treaty of Versailles (Llewellyn-Jones, 2006).

As Germany began rebuilding its U-boat force in 1935, European and North American navies prepared for another underwater war. Central to the war on submarines was the mobilization of acoustic knowledge to create new listening subjects who could distinguish between very similar-sounding echoes. To this end, the 
American and British navies established training programs during the interwar period, which expanded considerably during the Second World War. By 1945, in the U.S. alone, 16,000 personnel had been trained to operate sonar gear on board 2,300 new ships equipped for anti-submarine warfare (Lasky, 1977).

The British Admiralty also established sonar (or "asdic," in British naval parlance during the Second World War) training programs, such as the 14-week anti-submarine specialist course on the HMS Osprey, which began in 1924. For Captain R. Kerr, captain of the Second Destroyer Flotilla and senior instructor at the Admiralty's anti-submarine specialist school, finely tuning the subject's ears to hear minute differences between nearly identical echoes was crucial to the fleet's capacity to sink submarines. Underwater war, Kerr argued,

is an attempt to sink an invisible enemy by a sense which is not in every day use ... [and] efficiency depends on the appreciation of the quality of a sound. It is very much harder to distinguish between two notes of the same pitch played by different instruments, than to appreciate that a note is being struck. (as cited in Llewellyn-Jones, 2006, p. 23)

Underwater warfare strategy hinged on operators' capacity to separate the echoes bouncing off the target from ambient noise, including echo-like reverberations. Kerr continues, "The Asdic operator has to keep in mind what a submarine echo may sound like under all conditions and so distinguish it from other almost exactly similar sounds" (as cited in Llewellyn-Jones, 2006, p. 24). Underwater sound's material meanings were bound to knowledge about water conditions in particular areas of the ocean, which modulated, bent, sped up, and slowed down sound waves. In addition to the Admiralty's effort to record conditions in strategically important regions of the ocean, the training programs developed in the interwar period attempted to instill in operators awareness of underwater sound's material heterogeneity and tacit knowledge of the ocean's acoustic paths and velocity gradients so that they could feel their way through the undersea battlespace using ultrasonic beams (Hackmann, 1984).

Sonar and asdic operators were on the front lines of the subsea war, and they were encouraged to be aggressive in their hunt for submarines. This began in training sessions, where recruits spent days carrying out continuous attacks in sonar simulators (Curry, 1990). As Kerr suggested, the asdic operator's fluency in the language of underwater media, his ability interpret an echo not only as a sign of presence but also as a trace of the echo's source and as an arrow pointing to its future course, was the key to aggressive listening and to the fleet's subsea attack capabilities. Vibratory force became a component of fire control, and the operator became the primary conduit for feedback and corrective movement of the ship and the ship's weapons.

One of the key motivations for prioritizing projectile-like acoustic accuracy in interwar research was the development of new depth charges, which were launched ahead of the ship (rather than dropped behind it), and which were aimed according to information gleaned from ultrasonic sensing (Hackmann, 1984). To coordinate sensing and fire control, new mechanical systems were developed to convert the temporal gap between pulse and echo (as measured by a stopwatch inside the machine) into visual recordings of the submarine's course (Hackmann, 1984). Calculative tasks, such 
as determining the proximity and direction of the target, were delegated to machines, whereas interpretive tasks, such as deciding which echoes matter, were delegated to the listener. In this way, ultrasonics did much more than extend the field of perception; the system also divided perceptual labour between people and machines in a way that associated the former with the hermeneutics of echoes and the latter with the extraction of locative information.

The primary means of accelerating the operator's interpretation of echoes was the asdic or sonar simulator, which was developed during the interwar period to train listeners in the art of aggressive listening without the expense of using ships and submarines in open water. In the British navy's simulator, the control equipment of an asdic set was connected to a four-foot square table called an "attack table," the glass top of which held a sheet of plotting paper. Moveable projection units produced light spots on the paper from below to represent the ship and the submarine. The operator controlled the direction of pulses through the asdic set, and these pulses would appear as lines of light on the plotting paper. When the trainee's transmission hit a submarine, echoes would be heard through the headset (Hackmann, 1984). The goal of these exercises was not simply to monitor the water for submarines but to "sweep" or trace the target with acoustic waves and thereby open them up to weapons fire. Scientific knowledge enabled this new type of aggressive listening; oceanography and hydroacoustics formed the basis of precision underwater targeting..$^{10}$

The specialization of listening labour during the Second World War also meant that there was very little attempt on the part of command to convey the broader contexts of sonar activity. Frank Curry (1990), a Canadian asdic operator during the Second World War, wrote: "I cannot recall a single lecture, discussion or paper about the war at sea and our part in it. We were left entirely out of the big picture, expected merely to absorb training and carry out our duties" (p. 19). Anti-submarine officers were instead drilled in electrical engineering knowledge necessary for the maintenance of sonar equipment as well as what Curry (1940-1945) refers to as the "theory on asdic," that is, the oceanographic and acoustic knowledge that formed the basis of the Navy's strategies for interpreting echoes (p. 73). Electrical and acoustic phenomena were explicitly linked in the naval training discourses, and the electrical was taken as the starting point for understanding the acoustic. For example, once trainees understood "power" in the context of electricity, this became the basis for understanding power in the context of acoustics; both could be quantified as units of energy per second (Lasky, 1977). By way of these analogies, the trainee's knowledge of electrical phenomena was "transduced," so to speak, into acoustics and aggressive listening. Like an oscillator, trainees were expected to be able to switch from repairing circuits and splicing wires to the interpretation of echoes.

The links forged between electric and acoustic phenomena (and work) began to reshape the material meanings of sonar and orient the user to problems of time. This was particularly evident in the sonar operators' experience of electro-acoustic temporality. A significant characteristic of sonar operation was, to borrow Michel Chion's (1994) term from a very different context, the "temporalization of the ocean" (p. 17), that is, the modification of the subject's perception of time in subsea space by means 
of sound. The steady pulse of active sonar, and the irregular rhythm of echoes returning from objects, introduced new temporalities into the perception of the ocean. On the one hand, the pulse of sonar, which began the minute a ship left harbour and continued until the ship returned, provided reassurance that the ocean surrounding the ship or the convoy would be continuously probed for potential threats. On the other hand, echoed pings were often difficult to discern from reverberations; suspected submarine contacts and their characteristically sharp echoes were often lost as suddenly as they were found; and echoes of "non-subs" (e.g., whales) were frequently mistaken for submarines. The evenness of time generated by pings was thus punctuated by sudden periods of erratic time.

Moreover, despite the effort of scientists and navies to harness ocean water as the material substrate for underwater signification, the temporal linearization of the ocean induced by sonar's endless sequence of pulses was often disrupted by reverberation or echo-like sounds returning from various directions underwater by layers of water that reflected sound. Such disruptions led to false alarms, sending the crew to battle positions and subsequently provoking accusations that the sonar operators had gone "ping happy," which, as Curry (1990) explains, is "a reference to the 'ping' of the transmissions which hammered us every few seconds, with presumably disastrous effects on our mental faculties" (p. 18). In this way, the entire crew inhabited the erratic temporality generated by aggressive listening and tactile navigation. The convergence of electrical and acoustic domains in sonar allowed new forms of ocean surveillance and targeting as well as new types of auditory uncertainty, anxiety, and exhaustion stemming from extended periods of repetitive listening. The chain of signs between the listener and the threat - electrical charge, ultrasonic ping, ultrasonic echo, electrical charge, sonic echobecame longer, not shorter, in the transition from hydrophonic listening to ultrasonic detection. Each link in the chain of signs could be disrupted by an array of electrical or acoustic events, and since the operator only hears the (sonic) pulses, the system was liable to present superficial readings of a complex series of transductions.

By treating the ocean as a heterogeneous acoustic field, oceanographic knowledge, as articulated in asdic and sonar training, directed operators to treat water as a component of the medium. Sonar training impressed upon operators the fact that the characteristics of the water in a particular region determine the likelihood that acoustic waves will reach a target and return identifying or locative information to the listener. Aggressive listening was in this sense both enabled and constrained by oceanic water; no matter how sophisticated the gear, all systems were subject to fluctuations in water conditions, and thus the American and British navies conducted hundreds of sea trials along convoy routes and other strategically important areas to determine how the equipment would perform in different conditions (Hackmann, 1984). Producing accurate targeting systems was bound up with the production of accurate maps of oceanic water. Water itself may not have been a weapon, but oceanographic knowledge about regions and layers of water that affect the degree of aggressiveness that could be undertaken by listening systems was dangerous knowledge. The Navy thus attempted to monopolize this knowledge; literature describing oceanic features that affect sonar performance was classified in the years leading up the Second World War. 
The experience of underwater warfare rendered this knowledge of oceanic water practical. Pleased with the results of an attack exercise on a British submarine, Curry (1990) wrote the following entry in his war diary in 1943: "Water conditions excellent as our transmission boomed off her steel hull in clear sharp echoes" (p. 63). Several months later, after passing his Higher Submarine Detector exam, Curry tested his ship's asdic set in a quiet harbour by "pinging transmissions off all the neighboring ships and ... [following] a convoy down the harbor, ship by ship" (p. 85). "Good" water conditions meant that the water became pliable and transparent, allowing acoustic waves to cut through in relatively straight lines and return information-rich echoes to the ship with minimal noise. "Bad" conditions referred to environments that drew too much attention to water's mediating effects by bending or scattering the acoustic waves and thus limiting their range. New devices, such as the bathythermograph, which continuously measured and recorded the temperature of the water surrounding a vessel, enabled operators to calculate the range of the gear at any given moment. In this way, each anti-submarine vessel became a platform for the ongoing investigation of water's mediating effects. Yet the value of this knowledge in undersea warfare was that it could be used to cancel out these mediating effects. As the war drew to a close, the dominant discourse of sonar became marked by a desire for the medium to disappear.

\section{Conclusion}

From iceberg detectors to warning bells to ultrasonics, underwater audio media mutated rapidly in the first half of the early twentieth century and in the process they reshaped ideas, experiences, and uses of the ocean. While all of these technologies and practices were arguably different ways of doing the same thing-sending people to their deaths - knowledge of the ocean became effective in another, perhaps more important, way: the incorporation of listening techniques into machines, vessels, and bodies opened up a new front below the ocean surface for the perpetuation and elaboration of warfare waged by increasingly mobile machines. The deep sea had long been closed off from warfare due to its poverty of light; with mariners drilled in hydroacoustics and with vessels capable of converting sound into signal and back again, the ocean water became a rich repository of information about submerged objects and their trajectories. I have argued that sonar was one of the key ways in which sound became weaponized in the twentieth century, but it is also apparent from the foregoing discussion that the construction of acoustic weapons beginning with hydrophonic listening technologies in the First World War led to successive expansions of military power into habits of listening, ocean science, and the deep sea. What these changes suggest is that the constraints imposed on submarine movement, on listening, and on scientific knowledge were extremely productive in at least one sense: the ocean was gradually reconceptualized and enacted as a battlespace rather than as a surface. This vast, submerged, three-dimensional acoustic field subsequently enabled an expanding array of human activities in the deep sea, such as oceanography, seismographic exploration, and oil and mineral extraction.

The development of sonar as a medium required the development of new forms of listening. Early hydrophone systems attempted to establish a "direct connection" between source and listener, in an effort to repel ships away from underwater threats. 
Ocean navigation in this context required monitory listening and a basic repertoire of techniques for discerning the direction of the sound and the hazard signified by that sound. Active detection put tactility at the centre of targeting and navigation processes; meaning was located in the process of bouncing sound off the object's surface to discern its size and composition. The older hydrophonic notion that meaning was imparted from one location to another faded to the point that American naval scientists studying preparedness for submarine warfare during the interwar period became distressed about the lack of knowledge regarding direct sound emanating from ships ("sound signatures"), which could be used to identify those ships. Tactile navigation emerged as a solution to the problem of blindness in underwater environments where objects are invisible and often silent. In such conditions, the ocean must be "felt" rather than heard or seen directly. Yet the tactility of underwater listening has been supplemented by an array of visual and often written representations of those objects, from the stopwatch to the visual tracings of a submarine's course. The proliferation of visualization media in sonar development again altered the material meanings of the ocean; increasingly, underwater sound became something to be rationally decoded rather than intuitively felt.

The visual components of sonar systems have become so central to undersea acoustic sensing that there are now periodic calls within the naval engineering community for a return to listening. Although these disagreements are rich sites for exploring military conceptualizations of the senses and their differential epistemological value, sonar and the sensing techniques that it crystallized have always been audiovisual. Moreover, at least since the attempts in the late nineteenth century to measure sound's speed in bodies of water, there has been an effort to render acoustic "observations" or auditions as visual inscriptions so as to enable the collection, reproduction, and comparison of those observations. Thus, while sonar emerged out of, and contributed to, the early-twentieth-century scientific reassessment of hearing as a powerful mode of knowing and controlling the environment, military research on the "human factor" in sonar performance in the latter half of the twentieth century cast suspicion on the ear as a sensory organ that was particularly vulnerable to distraction, inattention, and fatigue. These findings, which were themselves circulated in the visual form of tables and charts, suggest that the history of sonar spans at least two major reassessments of the ear. While the first reassessment valorized hearing to the point of constructing an entirely new form of underwater warfare based on that sense, the second led to renewed distrust of hearing and of human perception more generally. It was this second reassessment that propelled and shaped global ocean surveillance systems during the Cold War, when underwater warfare strategy turned to the mobilization of automated sensing machines to monitor the ocean for us. Thus, beyond the question of hearing's status in the military's hierarchy of the senses is the question of how the spectre of nuclear war, particularly with the advent of submarine-launched nuclear ballistic missiles in the 1950s, problematized the fallibility of embodied sensing and propelled the development of discourses, practices, and technologies which attempted to compensate for that fallibility. 


\section{Acknowledgments}

The author wishes to thank Jonathan Sterne and two anonymous reviewers for their very helpful suggestions on earlier drafts of this article.

\section{Notes}

1. For instance, Innis (1951) traces the contributions of the competition between parchment and paper to a series of significant social changes in sixteenth-century Europe. Innis does not reduce the medium here to the printing press. Rather, he explores the heterogeneity of printed matter during this period, including the elaborate infrastructures of substrate production from the natural environment (e.g., labour, machinery, and transportation for producing paper from wood or rags), the importing of older signifying systems (e.g., Gothic script), new organizations (e.g., copyist guilds), and new cultural forms (e.g., folios, pamphlets, books). Innis' reference to the bias of space and time in the following passage thus needs to be understood as the trajectory of this entire system of interactions between social, cultural, and natural contexts:

Decline of the monopoly on knowledge based on parchment in which an ecclesiastical organization emphasized control over time followed the competition of paper which supported the growth of trade and of cities, the rise of vernaculars, and the increasing importance of lawyers, and emphasized the concept of space in nationalism. (p. 53)

2. In 1894, the British Parliament updated the Merchant Shipping Acts, which defined the largest category of ships as those over 10,000 gross register tons (GRT). By the 1910s, new passenger vessels were entering into service that were over four times this size, yet were treated by the legislation as though they were 10,000 GRT. One such ship was the RMs Titanic, which weighed 46,328 GRT (McLean \& Johnes, 2000).

3. New machines, such as the submersible ship and the torpedo, were specifically designed to challenge surface-based sea power. Thus, control of the surface of the ocean for commercial and military uses came to depend on control below the surface. In order to control the deep sea and the entities lurking within it, scientists attempted to make the deep accessible to the senses. In this way, sonar is what Judith Roof (2004) calls a "depth technology" that constructs depth as the locus of meaning and truth and which, in an effort to access those meanings and truths, renders depth as a surface that can be observed. While electromagnetic, optical (infrared), and other techniques were proposed in the twentieth century for sensing the deep sea, investment was directed primarily into sound-based techniques of sonar (or, asdic, as it was called in Britain until after the Second World War), and thus perceptions of the deep sea have been shaped by the notions of communication and subjectivity embodied by sonar.

4. As Frost (2001) notes, Fessenden was struck by the human toll of the Titanic disaster. But the loss of the Titanic also struck Fessenden, a Canadian who considered himself a British patriot, as a symbol of imperial Britain and motivated him to devise a new acoustic device to support British dominance of the ocean.

5. This strategy could have been particularly devastating in the "machine war" of 1914 to 1918 . Whereas in previous wars, food and other supplies could be foraged on the battlefront, the reliance on an assortment of machines, from telegraphs to tanks, meant that armies now depended on the continuous flow of machine parts from factories to the front lines. Unrestricted submarine warfare was designed to exploit the vulnerability of these long tails of equipment and supplies stretching across the Atlantic, the breakdown of which could lead to the rapid disintegration of the Allied forces.

6. During one of Langevin's 1917 experiments, "fish placed in the beam in the neighborhood of the source were killed immediately, and certain observers experienced a painful sensation on plunging the hand in this region" (as cited in Hackmann, 1984, p. 81).

7. The British government established the Board of Invention and Research (BIR) in July 1915 to provide government oversight and direction of scientific contributions to the war effort. Of its six divisions, 
the "submarines and wireless telegraphy" division received the largest government grant, most of which was earmarked for acoustic research (Hackmann, 1984, pp. 18-19). Dozens of universities, communications firms, and naval facilities were funded by the BIR to conduct submarine and anti-submarine research, development, and training (Hackmann, 1984). Within a few months of entering the war, the U.S. government established new laboratories dedicated to anti-submarine research and development. The Naval Consulting Board and the National Research Council recruited scientists from various firms, such as General Electric, Western Electric, and the Submarine Signal Company, to develop Uboat countermeasures at a facility in Nahant, Massachusetts (Frost, 2001; Weir, 2001). After meetings between the American, British, and French scientists involved in anti-submarine research, the U.S. Naval Experimental Station was established in New London, Connecticut. Ten civilian research groups were formed, the most prominent of which operated at Columbia University (Hackmann, 1984).

8. As Weir (2001) has shown, these alliances enabled the military to enlist prominent civilian scientists into underwater warfare research. The alliance between the marine science community and the U.S. Navy persisted in the interwar years. Marine science gained access to equipment only the Navy possessed. The Navy also benefited, since collaborations with civilian scientists helped to legitimate continued government support for naval operations during peacetime.

9. While sonic and ultrasonic detection are both "active" (they both use the echo-ranging technique), ultrasonic detection systems operate at much higher frequencies (at the upper end or even beyond the range of human hearing).

10. Scientific knowledge was incorporated into other areas of anti-submarine warfare as well. For example, mathematical analysis of U-boat diving patterns in the nascent field of operations research enabled more destructive patterns of depth charges to be launched into the ocean during the Second World War (Edwards, 1996).

\section{References}

Angus, Ian. (1998). The materiality of expression: Harold Innis' communication theory and the discursive turn in the human sciences. Canadian Journal of Communication, 23(1). URL: http://www.cjc-online.ca/index.php/journal/article/view/1020/926 [June 10, 2013].

Burnett, D.G. (2009). Hydrographic discipline and the navigators: Charting an "empire of commerce and science" in the nineteenth-century Pacific. In J.R. Akerman (Ed.), The imperial map: Cartography and the mastery of empire (pp. 185-259). Chicago, IL: University of Chicago Press.

Burnett, D.G. (2012). The sounding of the whale: Science and cetaceans in the twentieth century. Chicago, IL: University of Chicago Press.

Chion, Michel. (1994). Audio-vision: Sound on screen. New York, NY: Columbia University Press.

Christie, E.J. (2012). Writing in water. Postmedieval: A Journal of Medieval Cultural Studies, 3(1), 27-45.

Curry, Frank. (1940-1945). War diary. Frank Curry fonds, R2552-O-1-E, box 1. National Archives of Canada, Ottawa, Ontario.

Curry, Frank. (1990). War at sea: A Canadian seaman on the North Atlantic. Toronto, ON: Lugus Productions.

Edwards, Paul N. (1996). The closed world: Computers and the politics of discourse in Cold War America. Cambridge, MA: MIT Press.

Frost, Gary L. (2001). Inventing schemes and strategies: The making and selling of the Fessenden oscillator. Technology and Culture, 42(3), 462-488.

Gitelman, Lisa. (2004). Media, materiality, and the measure of the digital; or, The case of sheet music and the problem of piano rolls. In Lauren Rabinovitz \& Abraham Geil (Eds.), Memory bytes: History, technology, and digital culture (pp. 199-217). Durham, NC: Duke University Press.

Goodman, Steve. (2010). Sonic warfare: Sound, affect, and the ecology of fear. Cambridge, MA: MIT Press.

Goodwin, C. (1995). Seeing in depth. Social Studies of Science, 25(2), 237-274.

Hackmann, Willem Dirk. (1984). Seek and strike: Sonar, anti-submarine warfare and the Royal Navy, 1914-1954. London: Her Majesty's Stationery Office. 
Hall, Stuart. (1996). The West and the rest: Discourse and power. In Stuart Hall, David Held, Don Hubert, \& Kenneth Thompson (Eds.), Modernity: An introduction to modern societies (pp. 184-228). Cambridge, UK: Polity Press.

Harris, Chad. (2006). The omniscient eye: Satellite imagery, "battlespace awareness," and the structures of the imperialist gaze. Surveillance and Society, 4(1/2), 101-122.

Harvey, David. (1989). The condition of postmodernity: An enquiry into the origins of cultural change. Cambridge, MA: Blackwell.

Helmreich, Stefan. (2009). Alien ocean: Anthropological voyages in microbial seas. Berkeley, CA: University of California Press.

Hersey, J.B. (1977). A chronicle of man's use of ocean acoustics. Oceanus, 20(2), 8-21.

Hohler, Sabine. (2002). Depth records and ocean volumes: Ocean profiling by sounding technology, 1850-1930. History and Technology: An International Journal, 18(2), 119-154.

Innis, Harold. (1951). The bias of communication. Toronto, ON: University of Toronto Press.

Lasky, Marvin. (1977). Review of undersea acoustics to 1950. Journal of the Acoustical Society of America, 61(2), 283-297.

Latour, Bruno. (1990). Drawing things together. In Michael E. Lynch \& Steve Woolgar (Eds.), Representation in scientific practice (pp. 19-68). Cambridge, MA: MIT Press.

Law, John. (1986). On the methods of long-distance control: Vessels, navigation and the Portuguese route to India. In John Law (Ed.), Power, action, and belief: A new sociology of knowledge? (pp. 234-265). London: Routledge \& Kegan Paul.

Llewellyn-Jones, Malcolm. (2006). The Royal Navy and anti-submarine warfare, 1917-49. New York, NY: Routledge.

McLean, I., \& Johnes, M. (2000). 'Regulation run mad': The board of trade and the loss of the Titanic. Public Administration, 78(4), 729-749.

Peters, John Durham. (2003). Space, time and communication theory. Canadian Journal of Communication, 28(4). URL: http://www.cjc-online.ca/index.php/journal/article/view/1389/1467 [June 10, 2013].

Pritchard, James. (2011). A bridge of ships: Canadian shipbuilding during the Second World War. Montréal, QC: McGill-Queen's University Press.

Roof, Judith. (2004). Depth technologies. In S. R. Munt (Ed.), Technospaces (pp. 21-37). London: Continuum.

Said, Edward. (1979). Orientalism. Toronto, ON: Random House.

Steinberg, Philip E. (2001). The social construction of the ocean. Cambridge, UK: Cambridge University Press.

Sterne, Jonathan. (2003). The audible past: Cultural origins of sound reproduction. Durham, NC: Duke University Press.

Sterne, Jonathan, \& Akiyama, Mitchell. (2011). The recording that never wanted to be heard and other stories of sonification. In Trevor Pinch \& Karin Bijsterveld (Eds.), The Oxford handbook of sound studies (pp. 544-560). Oxford: Oxford University Press.

Thompson, Emily. (2002). The soundscape of modernity: Architectural acoustics and the culture of listening in America. Cambridge, MA: MIT Press.

Thompson, R.J. (2007). Crystal clear: The struggle for reliable communications technology in World War II. Piscataway, NJ: IEEE Press.

Van Creveld, Martin. (1985). Command in war. Cambridge, MA: Harvard University Press.

Van Creveld, Martin. (1989). Technology and war: From 2000 B.C. to the present. New York, NY: The Free Press.

Virilio, Paul. (1986). Speed and politics (Mark Polizzotti, Trans.). New York, NY: Semiotext(e). (Original work published 1977)

Weir, G.E. (2001). An ocean in common: American naval officers, scientists, and the ocean environment. College Station, TX: Texas A\&M University Press.

Weir, G.E. (2006). The American Sound Surveillance System: Using the ocean to hunt Soviet submarines, 1950-1961. International Journal of Naval History, 5(2), n.p. 
